\title{
The Effects of Community Home Visit and Peer Group Nutrition Intervention Delivery Platforms on Nutrition Outcomes in Low and Middle-Income Countries: A Systematic Review and Meta-Analysis
}

\author{
Amynah Janmohamed ${ }^{1}$, Nazia Sohani ${ }^{1}$, Zohra S Lassi ${ }^{2}$ and Zulfiqar A Bhutta ${ }^{1, *}$ \\ 1 Centre for Global Child Health, The Hospital for Sick Children, Toronto, ON M5G 2L3, Canada; \\ janmohamedamynah@gmail.com (A.J.); naziasohani@gmail.com (N.S.) \\ 2 Robinson Research Institute, University of Adelaide, Adelaide SA 5006, Australia; \\ zohra.lassi@adelaide.edu.au \\ * Correspondence: zulfiqar.bhutta@sickkids.ca; Tel.: +1-416-813-7654
}

Received: 16 December 2019; Accepted: 28 January 2020; Published: 10 February 2020

\begin{abstract}
Weak delivery systems reduce the potential of evidence-supported interventions to improve nutrition. We synthesized the evidence for the effectiveness of nutrition-specific intervention delivery platforms for improving nutrition outcomes in low and middle-income countries (LMIC). A systematic literature search for studies published from 1997 to June 2018 resulted in the inclusion of 83 randomized controlled trials (RCTs), quasi-randomized, and controlled before-after studies across a variety of delivery platforms. In this paper, we report on meta-analysed outcomes for community health worker (CHW) home visits and mother/peer group delivery platforms. Compared to care as usual, $\mathrm{CHW}$ home visits increased early initiation of breastfeeding (EIBF) (OR: 1.50; 95\% CI: 1.12, 1.99; $n=10$ RCTs) and exclusive breastfeeding (EBF) (OR: $4.42 ; 95 \%$ CI: 2.28, 8.56; $n=9$ RCTs) and mother/peer groups were effective for improving children's minimum dietary diversity (OR: 2.34; 95\% CI: 1.17, $4.70 ; n=4)$ and minimum meal frequency (OR: $2.31 ; 95 \%$ CI: $1.61,3.31 ; n=3)$. Pooled estimates from studies using both home visit and group platforms showed positive results for EIBF (OR: $2.13 ; 95 \%$ CI: $1.12,4.05 ; n=9$ ), EBF (OR: 2.43 ; 95\% CI: $1.70,3.46 ; n=12$ ), and < 5 wasting (OR: $0.77 ; 95 \%$ CI: $0.67,0.89 ; n=4)$. Our findings underscore the importance of interpersonal community platforms for improving infant and young child feeding practices and children's nutritional status in LMICs.
\end{abstract}

Keywords: nutrition; intervention; delivery; systematic review; low and middle-income country

\section{Introduction}

Poor nutrition in the early years of life poses substantial, and potentially lifelong, costs to health, development, and socioeconomic well-being [1,2]. Preventing the adverse effects of undernutrition requires essential nutrition actions during the critical first 1000 days of life [3]. Despite evidence-supported interventions to improve maternal and child nutrition [4], their potential gains are often thwarted by weak delivery systems preventing maximum population reach and impact $[5,6]$.

In most countries, a variety of intervention delivery platforms, or channels, are used to reduce access barriers to essential services. Notable examples are trained community health workers (CHWs) and mother/peer groups for health and nutrition promotion [7-9]. Though evidence supports CHW home visits and women's groups for improving maternal and newborn health in low and middle-income countries (LMICs) [10-12], evidence from high-quality studies involving such community platforms for delivering nutrition-specific interventions is limited across diverse populations [5]. This is partly 
due to limited knowledge surrounding how best to integrate nutrition-focused interventions into these routine activities at the country level [13].

Emerging evidence indicates that advancements in nutrition require nutrition-sensitive programmes that enhance the coverage and effectiveness of direct nutrition interventions [14]. Cash transfers requiring compliance with specific health/nutrition behaviours are commonly used in social protection/safety net programmes in LMICs $[15,16]$. Though evidence suggests they are effective for poverty reduction $[14,17,18]$, there is limited high-quality evidence on the effectiveness of conditional cash transfers (CCTs) for improving nutrition-specific outcomes among women and children [19]. Mobile health (mHealth) technologies (e.g., SMS messaging) are increasingly being used in global nutrition programming, yielding potentially cross-cutting benefits through linkages with community and financial platforms [20]. However, knowledge gaps remain surrounding the effectiveness of mHealth platforms for delivering nutrition-specific interventions [21,22].

We reviewed the available evidence to assess the effects of community-, financial- and technology-based nutrition intervention delivery platforms for improving nutrition outcomes in LMICs. In this paper, we report on meta-analysed outcomes for community health worker (CHW)/lay counselor home visits and mother/peer groups, which emerged as the most widely used community-based platforms for delivering nutrition-specific interventions in our review. While the multiplicity of health delivery platforms across LMICs is acknowledged, our review focused only on those delivering a nutrition-specific intervention or that integrated a direct nutrition component.

\section{Materials and Methods}

\subsection{Types of Studies}

We conducted the systematic review and meta-analysis following the Preferred Reporting Items for Systematic Reviews and Meta-Analyses (PRISMA) guidelines [23] and according to the study protocol [24]. We searched the Cochrane Central Register of Controlled Trials, Embase, MEDLINE, Scopus, and Web of Science for English-language studies published from 1997 to June 2018 using Medical Subject Heading (MeSH) terms and keywords (MEDLINE search strategy included in Table S1). In addition, ClinicalTrials.gov and the WHO International Clinical Trials Registry Platform were searched for ongoing trials and we examined the grey literature for relevant studies. Studies were included if they: (i) occurred in a LMIC, as per the World Bank [25] definition at the time of publication; (ii) utilized a community, financial and/or technology platform for delivering a nutrition-specific intervention; (iii) utilized a randomized, cluster-randomized, quasi-randomized, stepped-wedge, controlled before-after, or interrupted time series design with a control group; and (iv) examined a relevant outcome. Excluded studies did not include a control group.

\subsection{Outcomes}

The primary study outcomes were: early initiation of breastfeeding (EIBF) (breastfeeding within one hour of birth), exclusive breastfeeding (EBF) (up to 6 months), minimum dietary diversity (MDD) and minimum meal frequency (MMF) (based on WHO [26] guidelines), compliance with micronutrient supplementation, anthropometric measures (height/length, weight, body mass index, stunting, underweight, wasting), hemoglobin/anemia, and micronutrient status. No secondary outcomes were assessed. Duration of exposure and timing of outcome measurement were not restrictions for exclusion.

\subsection{Search Methods and Data Extraction}

Two reviewers screened titles and abstracts to identify potentially eligible studies using Covidence (Veritas Health Innovation, Melbourne, Australia). Full texts of selected articles were reviewed independently by two reviewers for eligibility based on predefined inclusion criteria, with discrepancies resolved by discussion. Double data extraction using standard forms was conducted for studies that 
met the inclusion criteria. Extracted data consisted of: (i) author, publication year, country, area; (ii) study design; (iii) study population characteristics; (iv) type of delivery platform; (v) description and duration of intervention(s); (vi) control group description; (vii) outcome measurement(s); and (viii) effect measure(s). Reference lists from included studies and relevant systematic reviews were also examined.

\subsection{Statistical Analysis}

Pooled estimates of outcome measures were calculated using random-effects models (inverse-variance method) in RevMan 5.3 (Cochrane Collaboration). Meta-analyses were conducted based on outcome and type of delivery platform and, when possible, were performed separately for randomized and non-randomized studies. Pooled estimates are presented as odds ratios (OR) with 95\% confidence intervals (CI). Where necessary, data conversions were made using available study data. For study outcomes measured at multiple time points (e.g., anthropometry), we selected similar measurements across studies based on what we considered to be the most clinically relevant follow-up period for the particular outcome. Statistical heterogeneity for included studies was assessed by visually examining forest plots and quantitatively using $\mathrm{Tau}^{2}, \mathrm{I}^{2}$, and significance of the chi-squared test. Sensitivity analyses were performed based on removing studies with outlying effect sizes.

\subsection{Quality Assessment}

Two reviewers independently assessed the risk of bias for all included studies using the Cochrane risk-of-bias tool [27] and the Cochrane Effective Practice and Organisation of Care (EPOC) guidelines [28] for randomized and non-randomized studies, respectively. As the blinding of study participants and intervention providers is relatively uncommon in behavioural intervention trials, we concluded that non-blinding posed a low risk of bias for outcomes we considered to be minimally affected by a lack of blinding. We used the GRADE method [29] to evaluate the overall quality of evidence and produce a summary of findings table for each meta-analysed outcome.

\section{Results}

\subsection{Search Results}

We identified a total of 20,661 records in the search, of which 5277 were duplicates, and 15,164 were excluded at the title/abstract screening stage. We reviewed 219 full-text articles for eligibility and a total of 83 studies were included in the full review (Figure 1). Table S2 summarizes the key characteristics of the CHW/lay counselor home visit and mother/peer group studies, which are the focus of this paper. These studies utilized one or both of these platforms to deliver nutrition education/behaviour change communication to mothers/caregivers of young children. 

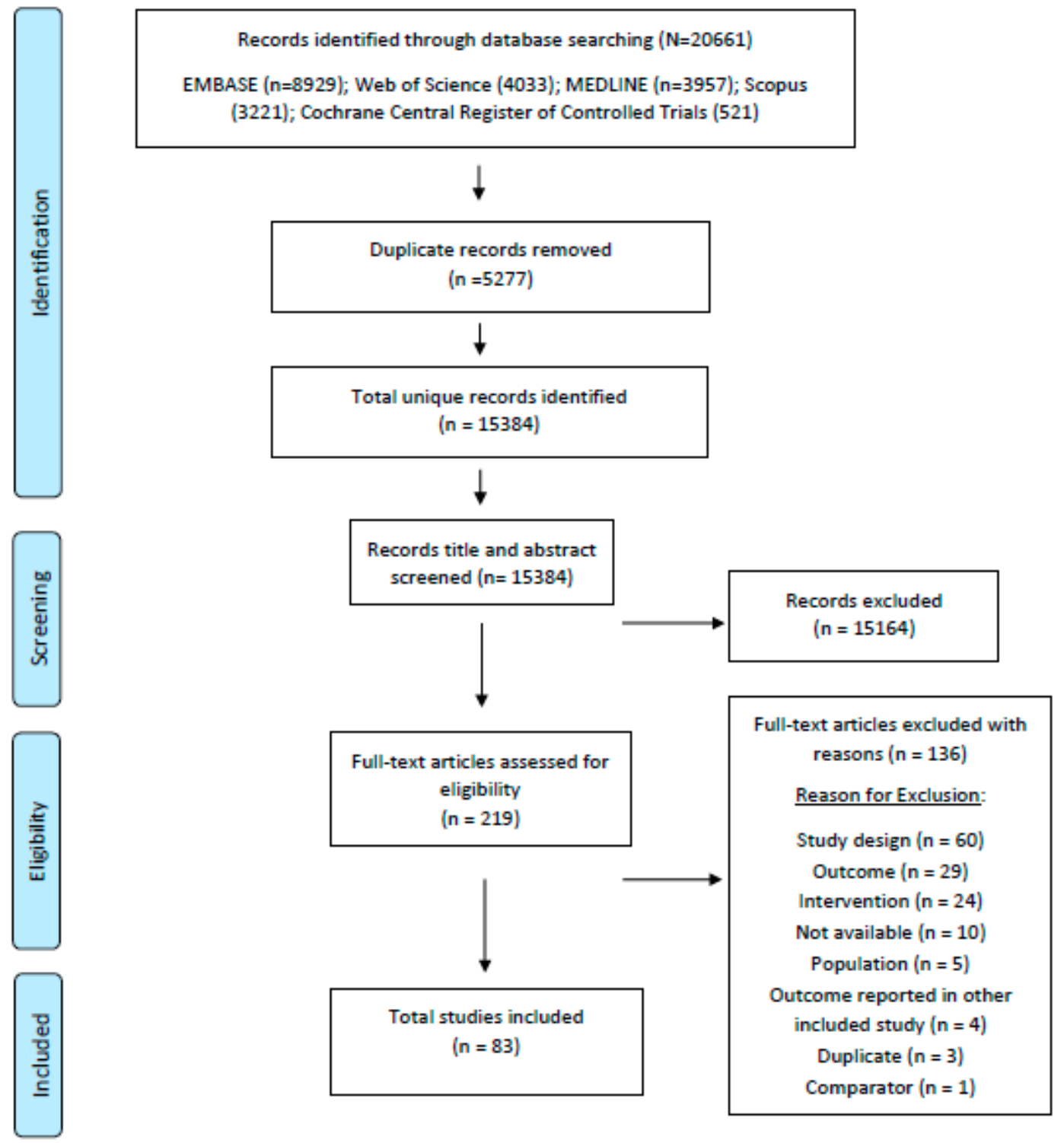

Figure 1. PRISMA diagram.

\subsection{CHW/Peer Counselor Home Visit Platform}

For the $\mathrm{CHW} /$ peer counselor home visit platform, we conducted meta-analyses for four outcomes: EIBF, EBF, $<5$ stunting and $<5$ underweight (Table 1). The pooled estimate for EIBF based on 10 RCTs showed a positive effect (OR: 1.50; 95\% CI: 1.12, 1.99) for home visits, compared to usual care (Figure 2). A smaller, though positive, effect was observed when excluding the Haider et al. study from the analysis (OR: 1.20; 95\% CI: 1.02, 1.41). A pooled analysis of non-randomized studies $(n=4)$ also revealed a higher likelihood of EIBF among mothers receiving home visits, as compared to those receiving usual care (OR: 1.80; 95\% CI: 1.17, 2.78). 
Table 1. Summary of outcomes for community healthcare worker (CHW)/peer counselor home visit platform.

\begin{tabular}{|c|c|c|c|c|c|}
\hline Outcomes & $\begin{array}{l}\text { Anticipated } \\
\text { Risk With } \\
\text { Care as Usual }\end{array}$ & $\begin{array}{c}\text { olute Effects } \\
\text { Risk With } \\
\text { Home Visits }\end{array}$ & $\begin{array}{c}\text { Relative Effect } \\
\text { (95\% CI) }\end{array}$ & $\begin{array}{c}\text { № of } \\
\text { Participants } \\
\text { (Studies) }\end{array}$ & $\begin{array}{c}\text { Certainty of } \\
\text { the Evidence } \\
\text { (GRADE) }\end{array}$ \\
\hline $\begin{array}{c}\text { Early initiation } \\
\text { of } \\
\text { breastfeeding } \\
\text { RCTs }^{\text {a }}\end{array}$ & 390 per 1000 & 490 per 1000 & $\begin{array}{c}\text { OR } 1.50 \\
(1.12 \text { to } 1.99)\end{array}$ & $\begin{array}{c}23,044 \\
(10)\end{array}$ & $\underset{\text { LOW }}{\bigoplus \bigoplus \bigcirc \bigcirc}$ \\
\hline $\begin{array}{c}\text { Early initiation } \\
\text { of } \\
\text { breastfeeding } \\
\text { non RCTs }^{\text {a }}\end{array}$ & 464 per 1000 & 609 per 1000 & $\begin{array}{c}\text { OR } 1.80 \\
(1.17 \text { to } 2.78)\end{array}$ & $\begin{array}{c}9816 \\
(4)\end{array}$ & $\underset{\text { LOW }}{\bigoplus \bigoplus \bigcirc \bigcirc}$ \\
\hline $\begin{array}{c}\text { Exclusive } \\
\text { breastfeeding } \\
\text { RCTs }^{b}\end{array}$ & 350 per 1000 & 704 per 1000 & $\begin{array}{c}\text { OR } 4.42 \\
(2.28 \text { to } 8.56)\end{array}$ & $\begin{array}{c}6046 \\
(9)\end{array}$ & $\underset{\text { LOW }}{\bigoplus \bigoplus \bigcirc \bigcirc}$ \\
\hline $\begin{array}{c}\text { Exclusive } \\
\text { breastfeeding } \\
\text { non RCTs }{ }^{\text {b }}\end{array}$ & 421 per 1000 & 768 per 1000 & $\begin{array}{c}\text { OR } 4.57 \\
\text { (1.36 to } 15.36)\end{array}$ & $\begin{array}{c}2532 \\
(3)\end{array}$ & $\underset{\text { LOW }}{\bigoplus \bigoplus \bigcirc \bigcirc}$ \\
\hline Stunting $^{c}$ & 431 per 1000 & 616 per 1000 & $\begin{array}{c}\text { OR } 2.12 \\
(0.46 \text { to } 9.74)\end{array}$ & $\begin{array}{c}4436 \\
(3)\end{array}$ & $\begin{array}{c}\bigoplus \bigcirc \bigcirc \bigcirc \\
\text { VERY LOW }\end{array}$ \\
\hline Underweight ${ }^{\mathrm{d}}$ & 379 per 1000 & 362 per 1000 & $\begin{array}{c}\text { OR } 0.93 \\
(0.82 \text { to } 1.06)\end{array}$ & $\begin{array}{c}4515 \\
(4)\end{array}$ & $\begin{array}{l}\bigoplus \text { LOW } \\
\text { Đo० }\end{array}$ \\
\hline
\end{tabular}

${ }^{\text {a }}$ Child is breastfed within one hour of birth. ${ }^{\mathrm{b}}$ Child is provided only breastmilk up to 4-6 months of age

c Height-for-age is more than two standard deviations below the WHO Child Growth Standards median.

d Weight-for-age is more than two standard deviations below the WHO Child Growth Standards median.

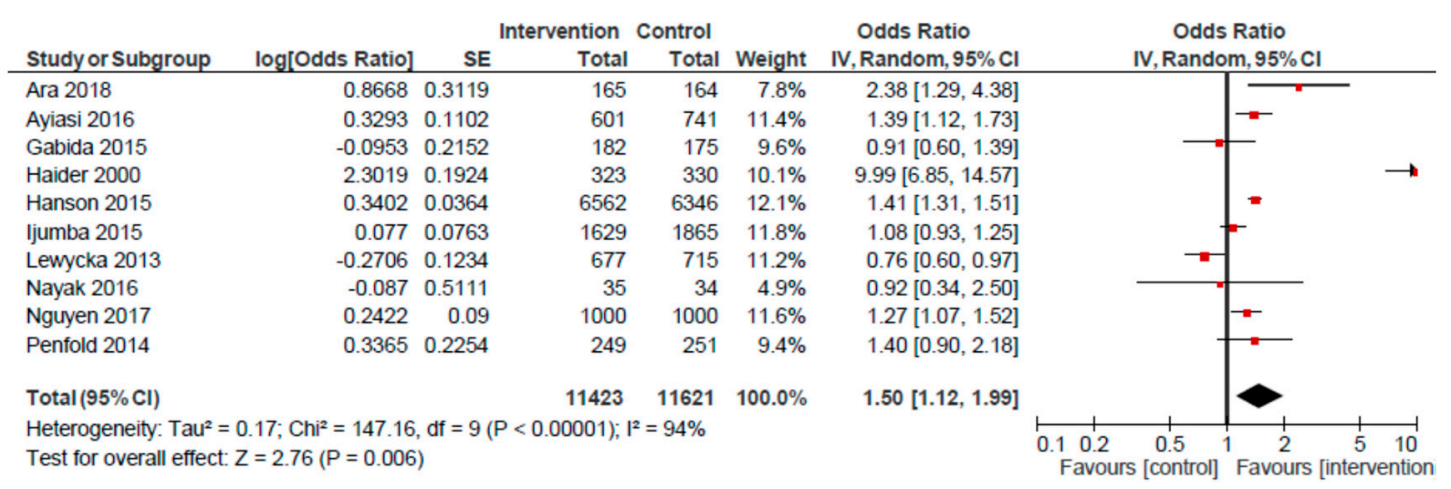

Figure 2. Forest plot of the meta-analysis of early initiation of breastfeeding for home visits (randomized studies).

An analysis of nine RCTs examining the association between the home visit platform and EBF produced an overall effect of 4.42 (95\% CI: 2.28, 8.56) (Figure 3). When removing the Haider et al. study, the odds of EBF remained significantly higher among mothers receiving home visits, compared to usual care (OR: $3.33 ; 95 \%$ CI: 1.94, 5.72). A pooled analysis of three non-randomized studies also revealed a positive effect (OR: 4.57; 95\% CI: 1.36, 15.36) on EBF for mothers receiving home visits, compared to those receiving usual care.

Meta-analyses revealed no significant impact of the home visit platform, compared to usual care, on $<5$ stunting (OR: $2.12 ; 95 \%$ CI: $0.46,9.74 ; n=3$ ) and a nearly significant $7 \%$ decrease in the likelihood of $<5$ underweight (OR: $0.93 ; 95 \%$ CI: $0.82,1.06 ; n=4$ ). 


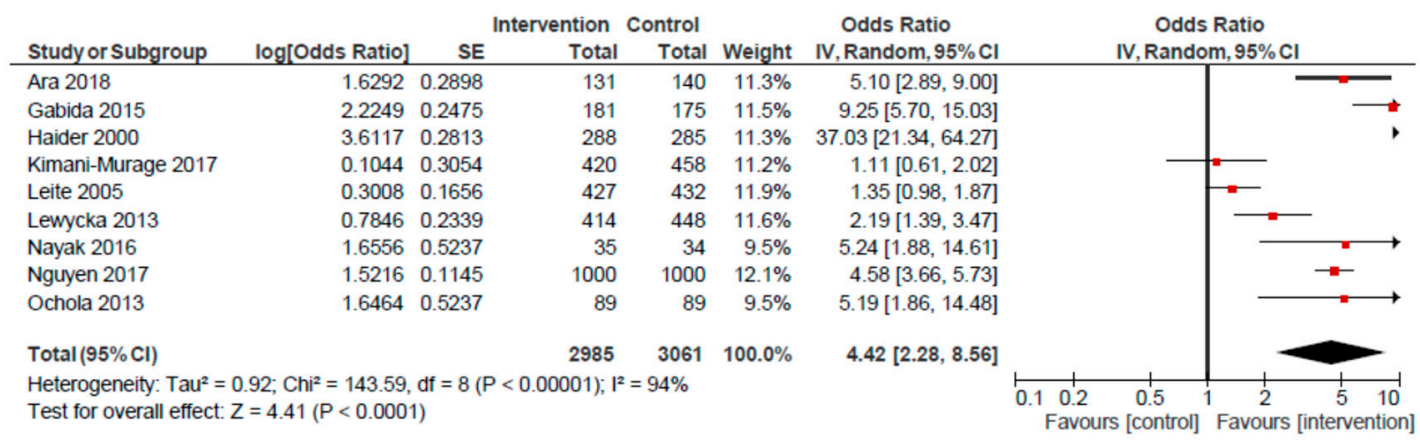

Figure 3. Forest plot of the meta-analysis of exclusive breastfeeding for home visits (randomized studies).

\subsection{Mother/Peer Group Platform}

For the mother/peer group platform, we conducted meta-analyses for seven outcomes: EIBF, EBF, MDD, MMF, and < 5 stunting, underweight and wasting (Table 2). Pooled estimates were non-significant for EIBF (OR: 1.10; 95\% CI: 0.92, 1.32; $n=5$ ), and EBF (OR: $1.78 ; 95 \%$ CI: $0.93,3.41 ; n=4$ ), as compared to usual care. A pooled analysis of four studies revealed a higher likelihood of MDD (OR: 2.34; 95\% CI: 1.17, 4.70) (Figure 4). However, removing the Negash et al. study resulted in a lower, and non-significant, effect on MDD (OR: 1.64; 95\% CI: 0.92, 2.93) for children of mothers participating in group sessions, as compared to usual care. A similarly positive meta-analysed effect was observed for MMF (OR: 2.31; 95\% CI: 1.61, 3.31, $n=3$ ) (Figure 5). Removing the Kang et al. study reduced the likelihood of MMF to 2.13 ( $95 \%$ CI: 1.55, 2.92) for the mother/peer group platform, but remained significantly higher, as compared to usual care.

Table 2. Summary of outcomes for mother/peer group platform.

\begin{tabular}{|c|c|c|c|c|c|}
\hline \multirow{2}{*}{ Outcomes } & \multicolumn{2}{|c|}{ Anticipated Absolute Effects } & \multirow{2}{*}{$\begin{array}{l}\text { Relative Effect } \\
\qquad(95 \% \text { CI) }\end{array}$} & \multirow{2}{*}{$\begin{array}{c}\text { № of } \\
\text { Participants } \\
\text { (Studies) }\end{array}$} & \multirow{2}{*}{$\begin{array}{c}\text { Certainty of } \\
\text { the Evidence } \\
\text { (GRADE) }\end{array}$} \\
\hline & $\begin{array}{l}\text { Risk with Care } \\
\text { as Usual }\end{array}$ & $\begin{array}{l}\text { Risk with Group } \\
\text { Sessions }\end{array}$ & & & \\
\hline $\begin{array}{l}\text { Early initiation } \\
\quad \text { of } \\
\text { breastfeeding a }\end{array}$ & 651 per 1000 & 672 per 1000 & $\begin{array}{c}\text { OR } 1.10 \\
(0.92 \text { to } 1.32)\end{array}$ & $\begin{array}{l}28,111 \\
(5)\end{array}$ & $\begin{array}{l}\bigoplus \bigoplus \bigoplus \bigcirc \\
\text { MODERATE }\end{array}$ \\
\hline $\begin{array}{c}\text { Exclusive } \\
\text { breastfeeding }\end{array}$ & 413 per 1000 & 556 per 1000 & $\begin{array}{c}\text { OR } 1.78 \\
(0.93 \text { to } 3.41)\end{array}$ & $\begin{array}{c}2900 \\
(4)\end{array}$ & $\begin{array}{l}\bigoplus \bigoplus \bigoplus \bigcirc \\
\text { MODERATE }\end{array}$ \\
\hline $\begin{array}{l}\text { Minimum } \\
\text { dietary } \\
\text { diversity }{ }^{c}\end{array}$ & 346 per 1000 & 554 per 1000 & $\begin{array}{c}\text { OR } 2.34 \\
(1.17 \text { to } 4.70)\end{array}$ & $\begin{array}{c}3701 \\
(4)\end{array}$ & $\underset{\text { LOW }}{\bigoplus \bigoplus \bigcirc \bigcirc}$ \\
\hline $\begin{array}{l}\text { Minimum meal } \\
\text { frequency } \mathrm{d}\end{array}$ & 808 per 1000 & 907 per 1000 & $\begin{array}{c}\text { OR } 2.31 \\
\text { (1.61 to } 3.31)\end{array}$ & $\begin{array}{l}2946 \\
(3)\end{array}$ & $\underset{\mathrm{HIGH}}{\bigoplus \bigoplus \bigoplus}$ \\
\hline Stunting ${ }^{\mathrm{e}}$ & 352 per 1000 & 315 per 1000 & $\begin{array}{c}\text { OR } 0.85 \\
(0.68 \text { to } 1.07)\end{array}$ & $\begin{array}{l}6077 \\
(3)\end{array}$ & $\begin{array}{c}\bigoplus \bigoplus \bigoplus \bigcirc \\
\text { MODERATE }\end{array}$ \\
\hline Underweight ${ }^{\mathrm{f}}$ & 382 per 1000 & 319 per 1000 & $\begin{array}{c}\text { OR } 0.76 \\
(0.53 \text { to } 1.07)\end{array}$ & $\begin{array}{c}6019 \\
(3)\end{array}$ & $\underset{\text { LOW }}{\bigoplus \bigoplus \circ O}$ \\
\hline Wasting $\mathrm{g}$ & 231 per 1000 & 206 per 1000 & $\begin{array}{c}\text { OR } 0.86 \\
(0.65 \text { to } 1.14)\end{array}$ & $\begin{array}{c}5924 \\
(3)\end{array}$ & $\underset{\text { LOW }}{\bigoplus \bigoplus \circ O}$ \\
\hline
\end{tabular}

${ }^{\mathrm{a}}$ Child is breastfed within one hour of birth. ${ }^{\mathrm{b}}$ Child is provided only breastmilk up to $4-6$ months of age ${ }^{\mathrm{c}}$ Child aged 6-23 months is fed a daily minimum of four out of seven food groups according to WHO guidelines [25]. ${ }^{d}$ Child aged 6-23 months is provided the appropriate number of daily solid/semi-solid/milk feeds (based on age and breastfeeding status) according to $\mathrm{WHO}$ guidelines [25]. ${ }^{\mathrm{e}}$ Height-for-age is more than two standard deviations below the WHO Child Growth Standards median. ${ }^{\mathrm{f}}$ Weight-for-age is more than two standard deviations below the WHO Child Growth Standards median. ${ }^{\mathrm{g}}$ Weight-for-height is more than two standard deviations below the WHO Child Growth Standards median. 


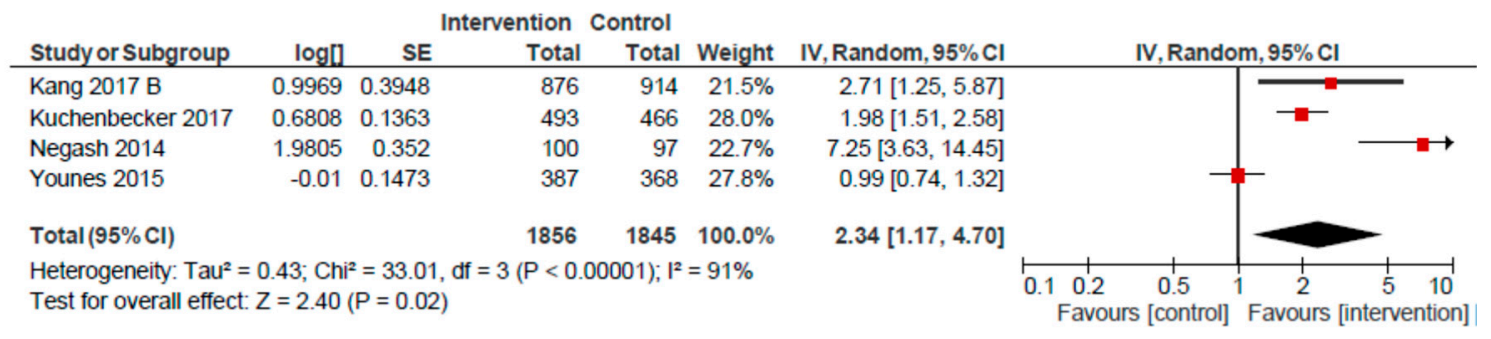

Figure 4. Forest plot of the meta-analysis of child minimum dietary diversity for mother/peer groups.

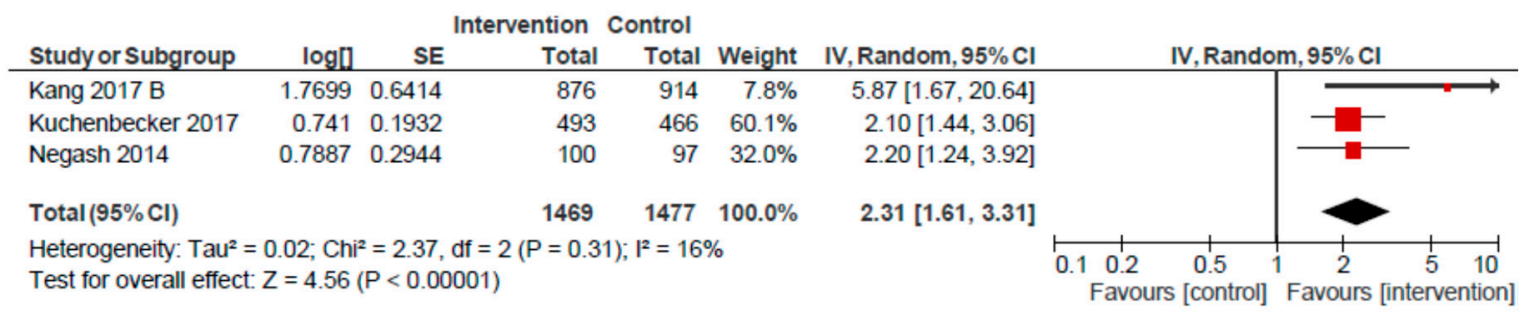

Figure 5. Forest plot of the meta-analysis of child minimum meal frequency for mother/peer groups.

In a pooled analysis of three studies that examined the effects of the group platform on $<5$ stunting, underweight, and wasting, compared to care as usual, there was a nearly significant $15 \%$ reduction in the odds of stunting (OR: $0.85 ; 95 \%$ CI: $0.68,1.07$ ) and a $24 \%$ reduction in the odds of underweight (OR: 0.76 ; $95 \%$ CI: 0.53, 1.07). For child wasting, the observed effect was 0.86 (95\% CI: 0.65, 1.14).

\subsection{Combined Home Visit and Group Platforms}

Through examining studies that used both home visit and group platforms for delivery of nutrition interventions, we explored the synergistic benefits of using both modalities for improving nutrition outcomes. Meta-analyses were conducted for EIBF, EBF and stunting underweight and wasting (Table 3). Pooled results showed a significantly higher likelihood of EIBF (OR: 2.13; 95\% CI: 1.12, 4.05, $n=9$ among mothers receiving home visits and participating in group sessions, compared to usual care (Figure 6). Excluding the Bhutta et al., Crookston et al., and Lamstein et al. studies reduced the likelihood of EIBF to a non-significant 1.15 (95\% CI: 0.82, 1.62). For EBF, the observed effect was 2.43 (95\% CI: 1.70, 3.46) across 12 studies (Figure 7). Removing the Bhandari et al. and Crookston et al. studies revealed a lower, though still significantly higher than in usual care, likelihood of EBF among mothers benefiting from home visits and group sessions (OR: 1.79; 95\% CI: 1.38, 2.32).

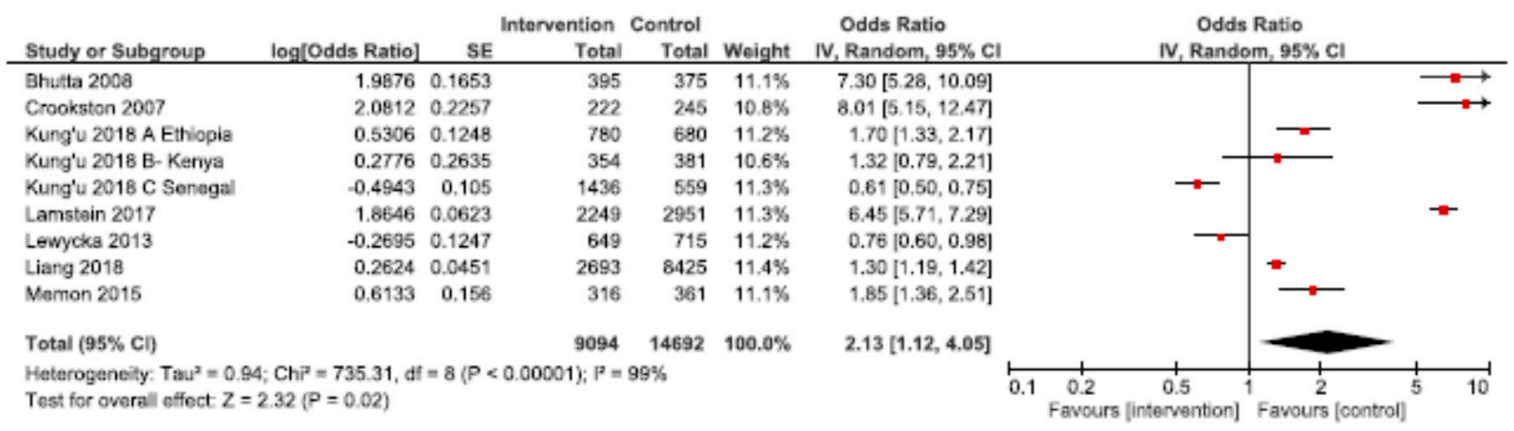

Figure 6. Forest plot of the meta-analysis of early initiation of breastfeeding for home visits and mother/peer groups. 


\begin{tabular}{|c|c|c|c|c|c|c|c|c|c|c|}
\hline \multirow[b]{2}{*}{ Study or Subgroup } & \multirow[b]{2}{*}{ log[Odds Ratio] } & \multicolumn{2}{|r|}{ Intervention } & \multicolumn{2}{|l|}{ Control } & \multirow{2}{*}{$\begin{array}{l}\text { Odds Ratio } \\
\text { IN, Random, } 95 \% \text { cl }\end{array}$} & \multirow{2}{*}{\multicolumn{4}{|c|}{$\begin{array}{c}\text { Odds Ratio } \\
\text { IV, Random, 95\% Cl }\end{array}$}} \\
\hline & & SE & Total & Total & Weight & & & & & \\
\hline Bhutta 2008 & 0.7148 & 0.1502 & 395 & 375 & $8.7 \%$ & $2.04[1,52,2.74]$ & & & & \\
\hline Brasington 2016 A- upper Egypt & 0.1242 & 0.0957 & 877 & 881 & $9.0 \%$ & $1.13[0.94,1.37]$ & & & & \\
\hline Crookston 2007 & 2.7293 & 0.2349 & 222 & 245 & $8.0 \%$ & $15.32[9.67,24.28]$ & & & & r \\
\hline Kung'u 2018 A Ethiopia & 0.9632 & 0.2018 & 780 & 680 & $8.3 \%$ & $2.62[1.76,3.89]$ & & & & \\
\hline Kung'u 2018 B- Kenya & 0.8154 & 0.159 & 354 & 381 & $8.6 \%$ & $2.26[1.65,3.09]$ & & & & \\
\hline Kung'u 2018 C Senegal & 0.3148 & 0.12 & 1436 & 569 & $8.9 \%$ & $1.37[1.08,1.73]$ & & & $\rightarrow-$ & \\
\hline Liang 2018 & 0.8416 & 0.1527 & 2693 & 8425 & $8.7 \%$ & $2.32[1.72,3.13]$ & & & & \\
\hline Nair 2017 & 0.0583 & 0.1834 & 1315 & 1368 & $8.4 \%$ & $1.05[0.74,1.52]$ & & & & \\
\hline Total $(95 \% \mathrm{Cl})$ & & & 10444 & 15569 & $100.0 \%$ & $2.43[1.70,3.46]$ & & & & \\
\hline $\begin{array}{l}\text { Hoterogeneity: } \text { Tau }^{2}=0.36 ; \text { Chi }^{2} \\
\text { Test for overall effect } Z=4.90(\mathrm{P}\end{array}$ & $\begin{array}{l}199.01, \mathrm{df}=11(\mathrm{P} . \\
<0.00001)\end{array}$ & $<0.0000$ & 1) $: P^{2}=94 \%$ & & & & \begin{tabular}{|l|l}
0.1 & 1 \\
0.2 \\
\end{tabular} & \begin{tabular}{c|}
1 \\
0.5 \\
gours [contronl
\end{tabular} & \begin{tabular}{|l} 
\\
1 \\
Favours
\end{tabular} & $\begin{array}{ll}1 \\
5 & 10 \\
\text { ntion] } & \end{array}$ \\
\hline
\end{tabular}

Figure 7. Forest plot of the meta-analysis of exclusive breastfeeding for home visits and mother/peer groups.

Table 3. Summary of outcomes for using both $\mathrm{CHW} /$ peer counselor home visit and mother/peer group platforms.

\begin{tabular}{|c|c|c|c|c|c|}
\hline \multirow{2}{*}{ Outcomes } & \multicolumn{2}{|c|}{ Anticipated Absolute Effects } & \multirow{2}{*}{$\begin{array}{l}\text { Relative Effect } \\
\text { (95\% CI) }\end{array}$} & \multirow{2}{*}{$\begin{array}{c}\text { № of } \\
\text { Participants } \\
\text { (Studies) }\end{array}$} & \multirow{2}{*}{$\begin{array}{c}\text { Certainty of } \\
\text { the Evidence } \\
\text { (GRADE) }\end{array}$} \\
\hline & $\begin{array}{l}\text { Risk with Care } \\
\text { as Usual }\end{array}$ & $\begin{array}{l}\text { Risk with Home } \\
\text { Visits and Group } \\
\text { Sessions }\end{array}$ & & & \\
\hline $\begin{array}{l}\text { Early initiation } \\
\text { of } \\
\text { breastfeeding }^{\text {a }}\end{array}$ & 443 per 1000 & 628 per 1000 & $\begin{array}{c}\text { OR } 2.13 \\
(1.12 \text { to } 4.05)\end{array}$ & $\begin{array}{l}23,786 \\
(9)\end{array}$ & $\begin{array}{c}\bigoplus \bigcirc \bigcirc \bigcirc \\
\text { VERY LOW }\end{array}$ \\
\hline $\begin{array}{c}\text { Exclusive } \\
\text { breastfeeding }\end{array}$ & 302 per 1000 & 513 per 1000 & $\begin{array}{c}\text { OR } 2.43 \\
(1.70 \text { to } 3.46)\end{array}$ & $\begin{array}{c}26,013 \\
(12)\end{array}$ & $\begin{array}{c}\bigoplus \bigcirc \bigcirc \bigcirc \\
\text { VERY LOW }\end{array}$ \\
\hline Stunting ${ }^{c}$ & 315 per 1000 & 309 per 1000 & $\begin{array}{c}\text { OR } 0.97 \\
(0.72 \text { to } 1.30)\end{array}$ & $\begin{array}{l}23,000 \\
(8)\end{array}$ & $\bigoplus_{\text {LOW }}^{\bigoplus ○ \bigcirc}$ \\
\hline Underweight $^{\mathrm{d}}$ & 146 per 1000 & 125 per 1000 & $\begin{array}{c}\text { OR } 0.84 \\
(0.61 \text { to } 1.14)\end{array}$ & $\begin{array}{c}19,108 \\
(6)\end{array}$ & $\begin{array}{c}\bigoplus \bigoplus_{\text {LOW }} \bigcirc \circ \\
\text {. }\end{array}$ \\
\hline Wasting ${ }^{\mathrm{e}}$ & 59 per 1000 & 46 per 1000 & $\begin{array}{c}\text { OR } 0.77 \\
\text { (0.67 to } 0.89)\end{array}$ & $\begin{array}{c}17,610 \\
(4)\end{array}$ & $\underset{\text { LOW }}{\bigoplus \bigoplus \bigcirc O}$ \\
\hline
\end{tabular}

${ }^{a}$ Child is breastfed within one hour of birth. ${ }^{b}$ Child is provided only breastmilk up to 4-6 months of age

${ }^{c}$ Height-for-age is more than two standard deviations below the WHO Child Growth Standards median.

d Weight-for-age is more than two standard deviations below the WHO Child Growth Standards median.

e Weight-for-height is more than two standard deviations below the WHO Child Growth Standards median.

The impact of the home visit and group session platform on stunting among children $<5$ years was 0.97 (95\% CI: 0.72, 1.30) across a pooled analysis of eight studies. The impact on $<5$ underweight was $0.84(95 \%$ CI: $0.61,1.14 ; n=6)$. A $23 \%$ reduction in the odds of $<5$ wasting (OR: $0.77 ; 95 \%$ CI: $0.67,0.89)$ was observed across four studies that used the home visit and group platform, compared to usual care (Figure 8).

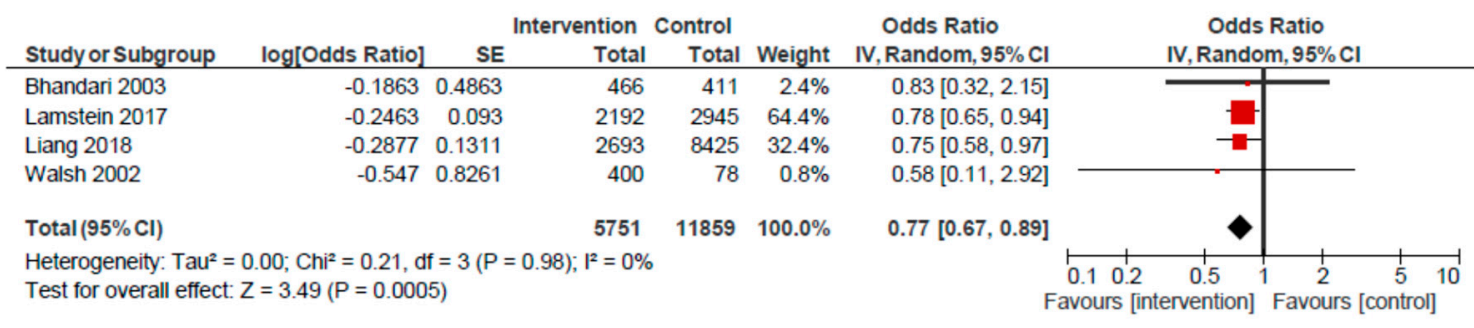

Figure 8. Forest plot of the meta-analysis of child wasting for home visits and mother/peer groups. 


\section{Discussion}

In this paper, we have summarized the available evidence for the effectiveness of $\mathrm{CHW} /$ peer counselor home visits and mother/peer groups for improving child nutrition outcomes in LMICs. These syntheses comprise a subset of results from a systematic review that examined various nutrition intervention delivery platforms in LMICs. Our findings reveal that one-to-one home visits by CHWs/lay peer counselors are effective for improving breastfeeding practices, which is consistent with prior evidence. Lewin et al. [30] showed that using lay health workers resulted in a higher likelihood of EIBF (RR: 1.36; 95\% CI: 1.14, 1.61) and EBF (RR: 2.78; 95\% CI: 1.74, 4.44), when compared to care as usual. Other reviews also concluded that peer support, in one-to-one or group settings, is effective for improving EBF practices [31-33]. The lack of effect of the mother/peer group platform on breastfeeding in our study was, therefore, unexpected and may have been due to differences in programme factors across studies, e.g., the frequency, content, and facilitation of group sessions. We were not able to separate the effects of using trained $\mathrm{CHWs}$ versus peer volunteer facilitators for conducting group sessions. Further research should explore whether facilitator characteristics may affect programme targets. Further, the higher likelihood of EIBF and EBF in pooled analyses of studies involving both home visit and mother/peer group platforms suggests home visits are important for breastfeeding promotion. We speculate that this is due to the one-to-one reinforcement of knowledge and skills acquired in group sessions and/or mothers feeling more comfortable discussing and practicing breastfeeding in the privacy of home settings. Household service delivery is emphasized in the 2013 Lancet nutrition series [4] as a means for increasing the coverage of nutrition intervention at the community level.

However, our results suggest that the mother/peer group platform is effective for improving the quantity and quality of young children's diets. This is likely due, in part, to participatory cooking demonstrations that frequently occur alongside counseling/coaching during group sessions and which have been shown to be effective for improving complementary feeding practices [34]. Our findings are consistent with a review of 36 studies that showed that women's groups focused on behaviour change are beneficial for improving child feeding practices in South Asia [13].

We focused on studies [35-90] involving CHW/lay counselor home visits and or mother/peer groups intended to improve the nutrition of young children. The absence of an observed effect of either platform on child stunting and underweight in our review was not unexpected, as effects of behavioural interventions on anthropometric outcomes are generally small, due to insufficient time periods to affect changes in child growth. Moreover, as intervention-impact pathways are influenced by a complex interplay of factors at all levels, demonstrating an attributable impact of behaviour-focused interventions on nutritional status is often challenging. Nonetheless, the observed $23 \%$ reduction in the odds of $<5$ wasting using the combined home visit and group platform is encouraging, and suggests acute thinness may be more responsive to education/behaviour change interventions than the long-term nutritional deficits underlying stunting.

The moderate to high study heterogeneity in our review was expected. Though too few studies prevented subgroup investigations of sources of heterogeneity, we speculate much of the heterogeneity is attributable to underlying differences in implementation-related factors affecting coverage levels achieved. Differences in coverage varied by platform, with home visits achieving higher average coverage than peer groups (59.5\% vs. 50.5\%) among included studies. In a study in Bangladesh, Owais et al. [86] reported that $83 \%$ of mothers received a $\mathrm{CHW}$ home visit within the previous month, while only $13 \%$ reported attending a mother-to-mother support group for nutrition education. In a Lady Health Worker study in Pakistan, Yousafzai et al. [90] reported that 75\% of households received monthly home visits, while 31\% of caregivers participated in monthly group meetings. Lastly, Nair et al. [85] reported that $80 \%$ of mothers received a home visit and $56 \%$ of mothers attended a group meeting during the previous three months, in a study examining the impact of women's groups and home-based counseling on child growth in Jharkhand and Odisha, India. 
Differences in study populations, CHW/lay counselor training/performance, exposure intensity (frequency of home visits and groups), and intervention duration also likely affected the coverage rates achieved. We were not able to assess the effects of length of intervention exposure due to the intervention period not being clearly specified in many studies. Dose-response analyses examining outcomes in relation to intervention duration and/or coverage would be useful and should be considered in future reviews.

All included studies in our review utilized an experimental design, though the overall quality of evidence was low for the majority of meta-analysed outcomes. A key limitation of our review was our inability to perform subgroup analyses to further investigate the high degree of heterogeneity, due to an insufficient number of studies. Though the inclusion of non-experimental studies in future reviews would generate a larger body of evidence, the introduction of additional biases would need to be weighed. Despite concerted efforts to select similar age/follow-up periods for anthropometric outcomes, variability across studies may have introduced some bias in the pooled analyses. However, this was not a concern for the infant and young child feeding (IYCF) outcomes, as time periods for ascertaining breastfeeding (0-6 months) and complementary feeding (6-23 months) practices were consistent across studies.

Our review strengthens the evidence through quantifying the effects of community home visits and peer groups and highlighting their potential value as platforms for improving IYCF practices in LMICs. As these tend to be established platforms within community-based child survival programmes in many countries, leveraging them for integrating nutrition-focused interventions that can be effectively provided by CHWs and through peer health promotion groups offers sizeable opportunities for nutrition behaviour change in these settings.

Therefore, the findings present an evidence-based rationale for continued investments in these community initiatives. Future research should account for platform-specific barriers affecting coverage to more broadly evaluate their effectiveness.

\section{Conclusions}

Knowledge of effective delivery modalities is needed to achieve maximum gains from evidence-supported interventions. In a landscape of multiple platforms and options, our findings indicate that community home visits and peer groups are important for improving nutrition-related behaviours across diverse contexts.

Supplementary Materials: The following are available online at http://www.mdpi.com/2072-6643/12/2/440/s1, Table S1: MEDLINE search strategy. Ovid MEDLINE(R) Epub Ahead of Print, In-Process \& Other Non-Indexed Citations, Ovid MEDLINE(R) Daily and Ovid MEDLINE(R) 1946 to Present, Table S2: Characteristics of included studies for home visit and group platforms.

Author Contributions: A.J. and N.S. conducted the review, data analysis, and drafted the manuscript; Z.S.L. provided technical expertise; Z.A.B. conceptualized the review and provided oversight for all aspects of the study. All authors approved the final version of the manuscript.

Funding: This research was funded by the Bill \& Melinda Gates Foundation, grant number OPP1137750.

Acknowledgments: We are grateful to Michelle Gaffey, Fahad Siddiqui, Emily Keats, and Muhammad Islam for their invaluable insight and technical support and thank Lily Ren for her assistance with developing the search strategy.

Conflicts of Interest: The authors declare no conflict of interest. The funder had no role in the design of the study; in the collection, analyses, or interpretation of data; in the writing of the manuscript, or in the decision to publish the results.

\section{References}

1. Martins, V.J.B.; Toledo Florêncio, T.M.M.; Grillo, L.P.; Franco, M.P.; Martins, P.A.; Clemente, A.P.G.; Santos, C.D.L.; Vieira, M.A.; Sawaya, A.L. Long-lasting effects of undernutrition. Int. J. Environ. Res. Public Health 2011, 8, 1817-1846. [CrossRef] [PubMed] 
2. Victora, C.G.; Adair, L.; Fall, C.; Hallal, P.C.; Martorell, R.; Richter, L.; Sachdev, H.S. Maternal and child undernutrition: Consequences for adult health and human capital. Lancet 2008, 371, 340-357. [CrossRef]

3. World Health Organization. Essential Nutrition Actions: Improving Maternal, Newborn, Infant and Young Child Health and Nutrition. World Health Organization: Geneva, Switzerland, 2013. Available online: https://www.who.int/nutrition/publications/infantfeeding/essential_nutrition_actions.pdf. (accessed on 10 January 2020).

4. Bhutta, Z.A.; Das, J.K.; Rizvi, A.; Gaffey, M.F.; Walker, N.; Horton, S.; Webb, P.; Lartey, A.; Black, R.E.; Lancet Nutrition Interventions Review Group, the Maternal and Child Nutrition Study Group. Evidence-based interventions for improvement of maternal and child nutrition: What can be done and at what cost? Lancet 2013, 382, 452-477. [CrossRef]

5. Menon, P.; Covic, N.M.; Harrigan, P.B.; Horton, S.E.; Kazi, N.M.; Lamstein, S.; Neufeld, L.; Oakley, E.; Pelletier, D. Strengthening implementation and utilization of nutrition interventions through research: A framework and research agenda. Ann. N. Y. Acad. Sci. 2014, 1332, 39-59. [CrossRef]

6. Ramakrishnan, U.; Imhoff-Kunsch, B.; Martorell, R. Maternal nutrition interventions to improve maternal, newborn, and child health outcomes. Nestle Nutr. Inst. Workshop Ser. 2014, 78, 71-80. [CrossRef]

7. Lassi, Z.S.; Kumar, R.; Bhutta, Z.A. Community-Based Care to Improve Maternal, Newborn, and Child Health. In Reproductive, Maternal, Newborn, and Child Health: Disease Control Priorities, 2rd ed.; Black, R.E., Laxminarayan, R., Temmerman, M., Walker, N., Eds.; The International Bank for Reconstruction and Development: Washington, DC, USA, 2016; Volume 2, Chapter 14. Available online: https://www.ncbi.nlm. nih.gov/books/NBK361898/. (accessed on 10 January 2020).

8. Shakya, P.; Kunieda, M.K.; Koyama, M.; Rai, S.S.; Miyaguchi, M.; Dhakal, S.; Sandy, S.; Sunguya, B.F.; Jimba, M. Effectiveness of community-based peer support for mothers to improve their breastfeeding practices: A systematic review and meta-analysis. PLoS ONE 2017, 12. [CrossRef]

9. Woldie, M.; Feyissa, G.T.; Admasu, B.; Hassen, K.; Mitchell, K.; Mayhew, S.; McKee, M.; Balabanova, D. Community health volunteers could help improve access to and use of essential health services by communities in LMICs: An umbrella review. Health Policy Plan 2018, 33, 1128-1143. [CrossRef]

10. Blanchard, A.K.; Prost, A.; Houweling, T.A.J. Effects of community health worker interventions on socioeconomic inequities in maternal and newborn health in low-income and middle-income countries: A mixed-methods systematic review. BMJ Glob. Health 2019, 4. [CrossRef]

11. World Health Organization. Recommendation on Community Mobilization Through Facilitated Participatory Learning and Action Cycles with Women's Groups for Maternal and Newborn Health. World Health Organization: Geneva, Switzerland, 2014. Available online: https:/www.who.int/maternal_child_adolescent/ documents/community-mobilization-maternal-newborn/en/ (accessed on 10 January 2020).

12. World Health Organization. Guideline: Counselling of Women to Improve Breastfeeding Practices. World Health Organization: Geneva, Switzerland, 2018. Available online: https:/www.who.int/nutrition/ publications/guidelines/counselling-women-improve-bf-practices/en/ (accessed on 10 January 2020).

13. Kumar, N.; Scott, S.; Menon, P.; Kannan, S.; Cunningham, K.; Tyagi, P.; Wable, G.; Raghunathan, K.; Quisumbing, A. Pathways from women's group-based programs to nutrition change in South Asia: A conceptual framework and literature review. Glob. Food Sec. 2018, 17, 172-185. [CrossRef]

14. Ruel, M.T.; Alderman, H.; Maternal and Child Nutrition Study Group. Nutrition-sensitive interventions and programmes: How can they help to accelerate progress in improving maternal and child nutrition? Lancet 2013, 382, 536-551. [CrossRef]

15. Lagarde, M.; Haines, A.; Palmer, N. Conditional cash transfers for improving uptake of health interventions in low- and middle-income countries: A systematic review. JAMA 2007, 298, 1900-1910. [CrossRef] [PubMed]

16. World Bank. The State of Social Safety Nets 2015; World Bank: Washington, DC, USA, 2015; Available online: http://documents.worldbank.org/curated/en/415491467994645020/The-state-of-social-safety-nets-2015 (accessed on 10 January 2020).

17. Owusu-Addo, E.; Renzaho, A.M.N.; Smith, B.J. The impact of cash transfers on social determinants of health and health inequalities in sub-Saharan Africa: A systematic review. Health Policy Plan 2018, 33, 675-696. [CrossRef] [PubMed] 
18. World Food Programme and Action Against Hunger. Impacts of Cash on Nutrition Outcomes: From Available Scientific Evidence to Informed Action; World Food Programme: Rome, Italy; Action Against Hunger: New York, NY, USA, 2018; Available online: https:/www.actioncontrelafaim.org/wp-content/uploads/2018/06/ R4ACT-Final-Report-230718.pdf (accessed on 10 January 2020).

19. de Groot, R.; Palermo, T.M.; Handa, S.; Ragno, L.P.; Peterman, A. Cash Transfers and Child Nutrition: Pathways and Impacts. Dev. Pol. Rev. 2017, 35. [CrossRef] [PubMed]

20. World Health Organization. New Horizons for Health through Mobile Technologies; World Health Organization: Geneva, Switzerland, 2011; Available online: https://www.who.int/goe/publications/goe_mhealth_web.pdf (accessed on 10 January 2020).

21. Hall, C.S.; Fottrell, E.; Wilkinson, S.; Byass, P. Assessing the impact of mHealth interventions in low- and middle-income countries-What has been shown to work? Glob. Health Action 2014, 27, 25606. [CrossRef]

22. Hingle, M.; Patrick, H. There are thousands of apps for that: Navigating mobile technology for nutrition education and behavior. J. Nutr. Educ. Behav. 2016, 48, 213-218. [CrossRef]

23. Moher, D.; Liberati, A.; Tetzlaff, J.; Altman, D.G.; PRISMA Group. Preferred reporting items for systematic reviews and meta-analyses: The PRISMA statement. PLoS Med. 2009, 21. [CrossRef]

24. Janmohamed, A.; Sohani, N.; Lassi, Z.S.; Bhutta, Z.A. PROTOCOL: The effectiveness of community, financial, and technology platforms for delivering nutrition-specific interventions in low- and middle-income countries: A systematic review. Campbell Syst. Rev. 2019, 15. [CrossRef]

25. World Bank. World Bank Country and Lending Groups; World Bank: Washington, DC, USA, 2019; Available online: https://datahelpdesk.worldbank.org/knowledgebase/articles/906519-world-bank-countryand-lending-groups (accessed on 10 January 2020).

26. World Health Organization; UNICEF; USAID; AED; UCDAVIS; IFPRI. Indicators for Assessing Infant and Young Child Feeding Practices; 2010. Available online: https:/www.who.int/nutrition/publications/infantfeeding/ 9789241599290/en/ (accessed on 10 January 2020).

27. Higgins, J.P.T.; Altman, D.G.; Gøtzsche, P.C.; Jüni, P.; Moher, D.; Oxman, A.D.; Savović, J.; Schulz, K.F.; Weeks, L.; Sterne, J.A.C. Cochrane Bias Methods Group; Cochrane Statistical Methods Group. The Cochrane Collaboration's tool for assessing risk of bias in randomised trials. BMJ 2011, 343. [CrossRef]

28. Cochrane Effective Practice and Organisation of Care (EPOC). EPOC Resources for Review Authors. 2017. Available online: https://epoc.cochrane.org/resources/epoc-resources-review-authors (accessed on 10 January 2020).

29. Schünemann, H.J.; Mustafa, R.; Brozek, J.; Santesso, N.; Alonso-Coello, P.; Guyatt, G.; Scholten, R.; Langendam, M.; Leeflang, M.M.; Akl, E.A.; et al. GRADE Working Group. GRADE Guidelines: 16. GRADE evidence to decision frameworks for tests in clinical practice and public health. J. Clin. Epidemiol. 2016, 76, 89-98. [CrossRef]

30. Lewin, S.; Munabi-Babigumira, S.; Glenton, C.; Daniels, K.; Bosch-Capblanch, X.; van Wyk, B.E.; Odgaard-Jensen, J.; Johansen, M.; Aja, G.N.; Zwarenstein, M.; et al. Lay health workers in primary and community health care for maternal and child health and the management of infectious diseases. Cochrane Database Syst. Rev. 2010, 2010, CD004015. [CrossRef]

31. Sudfeld, C.R.; Fawzi, W.W.; Lahariya, C. Peer support and exclusive breastfeeding duration in low and middle-income countries: A systematic review and meta-analysis. PLoS ONE 2012, 7. [CrossRef] [PubMed]

32. Jolly, K.; Ingram, L.; Khan, K.S.; Deeks, J.J.; Freemantle, N.; MacArthur, C. Systematic review of peer support for breastfeeding continuation: Metaregression analysis of the effect of setting, intensity, and timing. BMJ 2012, 344. [CrossRef] [PubMed]

33. Lassi, Z.S.; Haider, B.A.; Bhutta, Z.A. Community-based intervention packages for reducing maternal and neonatal morbidity and mortality and improving neonatal outcomes. Cochrane Database Syst. Rev. 2010, 11, CD007754. [CrossRef]

34. Sanghvi, T.; Seidel, R.; Baker, J.; Jimerson, A. Using behavior change approaches to improve complementary feeding practices. Matern. Child Nutr. 2017, 13. [CrossRef] [PubMed]

35. Ara, G.; Khanam, M.; Papri, N.; Nahar, B.; Haque, M.A.; Kabir, I.; Dibley, M.J. Peer counselling improves breastfeeding practices: A cluster randomized controlled trial in urban Bangladesh. Matern. Child Nutr. 2018, 14. [CrossRef] [PubMed] 
36. Aracena, M.; Krause, M.; Perez, C.; Mendez, M.J.; Salvatierra, L.; Soto, M.; Pantoja, T.; Navarro, S.; Salinas, A.; Farah, C.; et al. A cost-effectiveness evaluation of a home visit program for adolescent mothers. J. Health Psychol. 2009, 14, 878-887. [CrossRef] [PubMed]

37. Attanasio, O.P.; Fernandez, C.; Fitzsimons, E.O.A.; Grantham-McGregor, S.M.; Meghir, C.; Rubio-Codina, M. Using the infrastructure of a conditional cash transfer program to deliver a scalable integrated early child development program in Colombia: Cluster randomized controlled trial. BMJ 2014, 349. [CrossRef]

38. Ayiasi, R.M.; Kolsteren, P.; Batwala, V.; Criel, B.; Orach, C.G. Effect of village health team home visits and mobile phone consultations on maternal and newborn care practices in Masindi and Kiryandongo, Uganda: A community-intervention trial. PLoS ONE 2016, 11. [CrossRef]

39. Balaluka, G.B.; Nabugobe, P.S.; Mitangala, P.N.; Cobohwa, N.B.; Schirvel, C.; Dramaix, M.W.; Donnen, P. Community volunteers can improve breastfeeding among children under six months of age in the Democratic Republic of Congo crisis. Int. Breastfeed J. 2012, 7. [CrossRef]

40. Gabida, M.; Chemhuru, M.; Tshimanga, M.; Gombe, N.T.; Takundwa, L.; Bangure, D. Effect of distribution of educational material to mothers on duration and severity of diarrhoea and pneumonia, Midlands Province, Zimbabwe: A cluster randomized controlled trial. Int. Breastfeed J. 2015, 10. [CrossRef]

41. Haider, R.; Ashworth, A.; Kabir, I.; Huttly, S.R. Effect of community-based peer counsellors on exclusive breastfeeding practices in Dhaka, Bangladesh: A randomised controlled trial. Lancet 2000, 356, 1643-1647. [CrossRef]

42. Hanson, C.; Manzi, F.; Mkumbo, E.; Shirima, K.; Penfold, S.; Hill, Z.; Shamba, D.; Jaribu, J.; Hamisi, Y.; Soremekun, S.; et al. Effectiveness of a home-based counselling strategy on neonatal care and survival: A cluster-randomised trial in six districts of rural southern Tanzania. PLoS Med. 2015, 12. [CrossRef] [PubMed]

43. Ijumba, P.; Doherty, T.; Jackson, D.; Tomlinson, M.; Sanders, D.; Swanevelder, S.; Persson, L.A. Effect of an integrated community-based package for maternal and newborn care on feeding patterns during the first 12 weeks of life: A cluster-randomized trial in a South African township. Public Health Nutr. 2015, 18, 2660-2668. [CrossRef] [PubMed]

44. Kimani-Murage, E.W.; Griffiths, P.L.; Wekesah, F.M.; Wanjohi, M.; Muhia, N.; Muriuki, P.; Egondi, T.; Kyobutungi, C.; Ezeh, A.C.; McGarvey, S.T.; et al. Effectiveness of home-based nutritional counselling and support on exclusive breastfeeding in urban poor settings in Nairobi: A cluster randomized controlled trial. Glob. Health 2017, 13. [CrossRef]

45. Leite, A.J.; Puccini, R.F.; Atalah, A.N.; Alves Da Cunha, A.L.; Machado, M.T. Effectiveness of home-based peer counselling to promote breastfeeding in the northeast of Brazil: A randomized clinical trial. Acta Paediatr. 2005, 94, 741-746. [CrossRef]

46. McDougal, L.; Atmavilas, Y.; Hay, K.; Silverman, J.G.; Tarigopula, U.K.; Raj, A. Making the continuum of care work for mothers and infants: Does gender equity matter? Findings from a quasi-experimental study in Bihar, India. PLoS ONE 2017, 12. [CrossRef]

47. Nayak, D.S.; Kondagunta, N.; Kamath, V.G.; Kamath, A.; Nair, S. Impact of family level counselling on breast feeding practices and weight gain: A community based cluster randomized controlled trial. Int. J. Community Med. Public Health 2016, 3, 486-493. [CrossRef]

48. Nguyen, P.H.; Kim, S.S.; Sanghvi, T.; Mahmud, Z.; Tran, L.M.; Shabnam, S.; Aktar, B.; Haque, R.; Afsana, K.; Frongillo, E.A.; et al. Integrating nutrition interventions into an existing maternal, neonatal, and child health program increased maternal dietary diversity, micronutrient intake, and exclusive breastfeeding practices in Bangladesh: Results of a cluster-randomized program evaluation. J. Nutr. 2017, 147, 2326-2337. [CrossRef]

49. Nguyen, P.H.; Frongillo, E.A.; Sanghvi, T.; Kim, S.S.; Alayon, S.; Tran, L.M.; Mahmud, Z.; Aktar, B.; Menon, P. Importance of coverage and quality for impact of nutrition interventions delivered through an existing health programme in Bangladesh. Matern. Child Nutr. 2018, 14. [CrossRef]

50. Ochola, S.A.; Labadarios, D.; Nduati, R.W. Impact of counselling on exclusive breast-feeding practices in a poor urban setting in Kenya: A randomized controlled trial. Public Health Nutr. 2013, 16, 1732-1740. [CrossRef]

51. Penfold, S.; Manzi, F.; Mkumbo, E.; Temu, S.; Jaribu, J.; Shamba, D.D.; Mshinda, H.; Cousens, S.; Marchant, T.; Tanner, M.; et al. Effect of home-based counselling on newborn care practices in southern Tanzania one year after implementation: A cluster-randomised controlled trial. BMC Pediatr. 2014, 14. [CrossRef] [PubMed] 
52. Rahman, M.; Yunus, F.M.; Shah, R.; Jhohura, F.T.; Mistry, S.K.; Quayyum, T.; Aktar, B.; Afsana, K. A controlled before-and-after perspective on the improving maternal, neonatal, and child survival program in rural Bangladesh: An impact analysis. PLoS ONE 2016, 11. [CrossRef] [PubMed]

53. Risonar, M.G.; Rayco-Solon, P.; Tengco, L.W.; Sarol, J.N., Jr.; Paulino, L.S.; Solon, F.S. Effectiveness of a redesigned iron supplementation delivery system for pregnant women in Negros Occidental, Philippines. Public Health Nutr. 2009, 12, 932-940. [CrossRef] [PubMed]

54. Saleem, A.F.; Mahmud, S.; Baig-Ansari, N.; Zaidi, A.K.M. Impact of maternal education about complementary feeding on their infants' nutritional outcomes in low- and middle-income households: A community-based randomized interventional study in Karachi, Pakistan. J. Health Popul. Nutr. 2014, 32, 623-633.

55. Singh, V.; Ahmed, S.; Dreyfuss, M.L.; Kiran, U.; Chaudhery, D.N.; Srivastava, V.K.; Ahuja, R.C.; Baqui, A.H.; Darmstadt, G.L.; Santosham, M.; et al. An integrated nutrition and health program package on IYCN improves breastfeeding but not complementary feeding and nutritional status in rural northern India: A quasi-experimental randomized longitudinal study. PLOS ONE 2017, 12. [CrossRef]

56. Singh, V.; Ahmed, S.; Dreyfuss, M.L.; Kiran, U.; Chaudhery, D.N.; Srivastava, V.K.; Ahuja, R.C.; Baqui, A.H.; Darmstadt, G.L.; Santosham, M.; et al. Non-governmental organization facilitation of a community-based nutrition and health program: Effect on program exposure and associated infant feeding practices in rural India. PLoS ONE 2017, 12. [CrossRef]

57. Vir, S.C.; Kalita, A.; Mondal, S.; Malik, R. Impact of community-based mitanin programme on undernutrition in rural Chhattisgarh State, India. Food Nutr. Bull. 2014, 35, 83-91. [CrossRef]

58. Zhou, H.; Sun, S.; Luo, R.; Sylvia, S.; Yue, A.; Shi, Y.; Zhang, L.; Medina, A.; Rozelle, S. Impact of text message reminders on caregivers' adherence to a home fortification program against child anemia in rural western China: A cluster-randomized controlled trial. Am. J. Public Health 2016, 106, 1256-1262. [CrossRef]

59. Fottrell, E.; Azad, K.; Kuddus, A.; Younes, L.; Shaha, S.; Nahar, T.; Aumon, B.H.; Hossen, M.; Beard, J.; Hossain, T.; et al. The effect of increased coverage of participatory women's groups on neonatal mortality in Bangladesh: A cluster randomized trial. JAMA Pediatr. 2013, 167, 816-825. [CrossRef]

60. Harris-Fry, H.A.; Azad, K.; Younes, L.; Kuddus, A.; Shaha, S.; Nahar, T.; Hossen, M.; Costello, A.; Fottrell, E. Formative evaluation of a participatory women's group intervention to improve reproductive and women's health outcomes in rural Bangladesh: A controlled before and after study. J. Epidemiol. Community Health 2016, 70, 663-670. [CrossRef]

61. Kang, Y.; Cha, S.; Yeo, S.; Christian, P. Implementation, utilization and influence of a community-based participatory nutrition promotion programme in rural Ethiopia: Programme impact pathway analysis. Public Health Nutr. 2017, 20, 2004-2015. [CrossRef] [PubMed]

62. Kang, Y.; Suh, Y.K.; Debele, L.; Juon, H.S.; Christian, P. Effects of a community-based nutrition promotion programme on child feeding and hygiene practices among caregivers in rural Eastern Ethiopia. Public Health Nutr. 2017, 20, 1461-1472. [CrossRef] [PubMed]

63. Kang, Y.; Kim, S.; Sinamo, S.; Christian, P. Effectiveness of a community-based nutrition programme to improve child growth in rural Ethiopia: A cluster randomized trial. Matern. Child Nutr. 2017, 13. [CrossRef] [PubMed]

64. Kuchenbecker, J.; Reinbott, A.; Mtimuni, B.; Krawinkel, M.B.; Jordan, I. Nutrition education improves dietary diversity of children 6-23 months at community-level: Results from a cluster randomized controlled trial in Malawi. PLoS ONE 2017, 12. [CrossRef]

65. Lewycka, S.; Mwansambo, C.; Rosato, M.; Kazembe, P.; Phiri, T.; Mganga, A.; Chapota, H.; Malamba, F.; Kainja, E.; Newell, M.L.; et al. Effect of women's groups and volunteer peer counselling on rates of mortality, morbidity, and health behaviours in mothers and children in rural Malawi (MaiMwana): A factorial, cluster-randomised controlled trial. Lancet 2013, 381, 1721-1735. [CrossRef]

66. More, N.S.; Bapat, U.; Das, S.; Alcock, G.; Patil, S.; Porel, M.; Vaidya, L.; Fernandez, A.; Joshi, W.; Osrin, D. Community mobilization in Mumbai slums to improve perinatal care and outcomes: A cluster randomized controlled trial. PLoS Med. 2012, 9. [CrossRef]

67. Mushaphi, L.F.; Dannhauser, A.; Walsh, C.M.; Mbhenyane, X.G.; van Rooyen, F.C. Effect of a nutrition education programme on nutritional status of children aged 3-5 years in Limpopo Province, South Africa. S. Afr. J. Child. Health 2015, 9, 98-102. [CrossRef] 
68. Negash, C.; Belachew, T.; Henry, C.J.; Kebebu, A.; Abegaz, K.; Whiting, S.J. Nutrition education and introduction of broad bean-based complementary food improves knowledge and dietary practices of caregivers and nutritional status of their young children in Hula, Ethiopia. Food Nutr. Bull. 2014, 35, 480-486. [CrossRef]

69. Tripathy, P.; Nair, N.; Sinha, R.; Rath, S.; Gope, R.K.; Roy, S.S.; Bajpai, A.; Singh, V.; Nath, V.; Ali, S.; et al. Effect of participatory women's groups facilitated by Accredited Social Health Activists on birth outcomes in rural eastern India: A cluster-randomised controlled trial. Lancet Glob. Health 2016, 4. [CrossRef]

70. Yadav, D.K.; Gupta, N.; Shrestha, N.; Kumar, A.; Bose, D.K. Community based nutrition education for promoting nutritional status of children under three years of age in rural areas of Mahottari District of Nepal. J. Nepal Paediatr. Soc. 2015, 34, 181-187. [CrossRef]

71. Younes, L.; Houweling, T.A.; Azad, K.; Kuddus, A.; Shaha, S.; Haq, B.; Nahar, T.; Hossen, M.; Beard, J.; Copas, A.; et al. The effect of participatory women's groups on infant feeding and child health knowledge, behaviour and outcomes in rural Bangladesh: A controlled before-and-after study. J. Epidemiol. Community Health 2015, 69, 374-381. [CrossRef] [PubMed]

72. Saville, N.M.; Shrestha, B.P.; Style, S.; Harris-Fry, H.; Beard, J.; Sen, A.; Jha, S.; Rai, A.; Paudel, V.; Sah, R.; et al. Impact on birth weight and child growth of Participatory Learning and Action women's groups with and without transfers of food or cash during pregnancy: Findings of the low birth weight South Asia cluster-randomised controlled trial (LBWSAT) in Nepal. PLoS ONE 2018, 13. [CrossRef] [PubMed]

73. Bhandari, N.; Bahl, R.; Mazumdar, S.; Martines, J.; Black, R.E.; Bhan, M.K.; Infant Feeding Study Group. Effect of community-based promotion of exclusive breastfeeding on diarrhoeal illness and growth: A cluster randomised controlled trial. Lancet 2003, 361, 1418-1423. [CrossRef]

74. Bhandari, N.; Mazumder, S.; Bahl, R.; Martines, J.; Black, R.E.; Bhan, M.K. Infant Feeding Study Group. An educational intervention to promote appropriate complementary feeding practices and physical growth in infants and young children in Rural Haryana, India. J. Nutr. 2004, 134, 2342-2348. [CrossRef]

75. Brasington, A.; Abdelmegeid, A.; Dwivedi, V.; Kols, A.; Kim, Y.M.; Khadka, N.; Rawlins, B.; Gibson, A. Promoting healthy behaviors among Egyptian mothers: A quasi-experimental study of a health communication package delivered by community organizations. PLoS ONE 2016, 11. [CrossRef] [PubMed]

76. Brenner, J.L.; Kabakyenga, J.; Kyomuhangi, T.; Wotton, K.A.; Pim, C.; Ntaro, M.; Bagenda, F.N.; Gad, N.R.; Godel, J.; Kayizzi, J.; et al. Can volunteer community health workers decrease child morbidity and mortality in southwestern Uganda? An impact evaluation. PLoS ONE 2011, 6. [CrossRef]

77. Bhutta, Z.A.; Memon, Z.A.; Soofi, S.; Salat, M.S.; Cousens, S.; Martines, J. Implementing community-based perinatal care: Results from a pilot study in rural Pakistan. Bull. World Health Organ. 2008, 86, 452-459. [CrossRef] [PubMed]

78. Crookston, B.T.; Dearden, K.A.; Chan, K.; Chan, T.; Stoker, D.D. Buddhist nuns on the move: An innovative approach to improving breastfeeding practices in Cambodia. Matern. Child Nutr. 2007, 3, 10-24. [CrossRef]

79. Fenn, B.; Bulti, A.T.; Nduna, T.; Duffield, A.; Watson, F. An evaluation of an operations research project to reduce childhood stunting in a food-insecure area in Ethiopia. Public Health Nutr. 2012, 15, 1746-1754. [CrossRef]

80. Kung'u, J.K.; Pendame, R.; Ndiaye, M.B.; Gerbaba, M.; Ochola, S.; Faye, A.; Basnet, S.; Frongillo, E.A.; Wuehler, S.; De-Regil, L.M. Integrating nutrition into health systems at community level: Impact evaluation of the community-based maternal and neonatal health and nutrition projects in Ethiopia, Kenya, and Senegal. Matern. Child Nutr. 2018, 14. [CrossRef]

81. Lamstein, S.; Perez-Escamilla, R.; Koniz-Booher, P.; Begin, F.; Adeyemi, S.; Kaligirwa, C.; Isokpunwu, C.; Adebisi, B. The Community Infant and Young Child Feeding Counselling Package in Kaduna State, Nigeria: A Mixed Methods Evaluation. Final Summary Report. Strengthening Partnerships, Results, and Innovations in Nutrition Globally (SPRING) project: Arlington, VA, USA, 2018. Available online: https://www.springnutrition.org/sites/default/files/publications/reports/nigeria_ciycf_eval_rep_15-2-18.pdf (accessed on 10 January 2020).

82. Liang, W.; Xing, Y.; Pang, M.; Wang, D.; Yan, H. Community health education improves child health care in Rural Western China. BMC Pediatr. 2018, 18. [CrossRef] [PubMed]

83. Mayhew, M.; Ickx, P.; Stanekzai, H.; Mashal, T.; Newbrander, W. Improving nutrition in Afghanistan through a community-based growth monitoring and promotion programme: A pre-post evaluation in five districts. Glob. Public Health 2014, 9 (Suppl. 1), S58-S75. [CrossRef] [PubMed] 
84. Memon, Z.A.; Khan, G.N.; Soofi, S.B.; Baig, I.Y.; Bhutta, Z.A. Impact of a community-based perinatal and newborn preventive care package on perinatal and neonatal mortality in a remote mountainous district in Northern Pakistan. BMC Pregnancy Childbirth 2015, 15. [CrossRef]

85. Nair, N.; Tripathy, P.; Sachdev, H.S.; Pradhan, H.; Bhattacharyya, S.; Gope, R.; Gagrai, S.; Rath, S.; Rath, S.; Sinha, R.; et al. Effect of participatory women's groups and counselling through home visits on children's linear growth in rural eastern India (CARING trial): A cluster-randomised controlled trial. Lancet Glob. Health 2017, 5. [CrossRef]

86. Owais, A.; Schwartz, B.; Kleinbaum, D.G.; Suchdev, P.S.; Faruque, A.S.G.; Das, S.K.; Rahman, S.; Stein, A.D. A Nutrition Education Program in Rural Bangladesh Was Associated with Improved Feeding Practices but Not with Child Growth. J. Nutr. 2017, 147, 948-954. [CrossRef]

87. Rockers, P.C.; Fink, G.; Zanolini, A.; Banda, B.; Biemba, G.; Sullivan, C.; Mutembo, S.; Silavwe, V.; Hamer, D.H. Impact of a community-based package of interventions on child development in Zambia: A cluster-randomised controlled trial. BMJ Glob. Health 2016, 1. [CrossRef]

88. Shi, L.; Zhang, J.; Wang, Y.; Caulfield, L.E.; Guyer, B. Effectiveness of an educational intervention on complementary feeding practices and growth in rural China: A cluster randomised controlled trial. Public Health Nutr. 2010, 13, 556-565. [CrossRef]

89. Walsh, C.M.; Dannhauser, A.; Joubert, G. The impact of a nutrition education programme on the anthropometric nutritional status of low-income children in South Africa. Public Health Nutr. 2002, 5, 3-9. [CrossRef]

90. Yousafzai, A.K.; Rasheed, M.A.; Rizvi, A.; Armstrong, R.; Bhutta, Z.A. Effect of integrated responsive stimulation and nutrition interventions in the Lady Health Worker programme in Pakistan on child development, growth, and health outcomes: A cluster-randomised factorial effectiveness trial. Lancet 2014, 384, 1282-1293. [CrossRef]

(C) 2020 by the authors. Licensee MDPI, Basel, Switzerland. This article is an open access article distributed under the terms and conditions of the Creative Commons Attribution (CC BY) license (http://creativecommons.org/licenses/by/4.0/). 